\title{
Prognosis of patients with retinal embolism
}

\author{
R S HOWARD, R W ROSS RUSSELL
}

From the Departments of Neurology and Medical Ophthalmology, St Thomas' Hospital, London, UK

SUMMARY Eighty-five patients with retinal emboli, visible ophthalmoscopically, were studied retrospectively. All the patients had presented with transient or permanent visual loss. Follow up from the time of presentation was one year to 12 years with a mean of 4.5 years. Life expectancy in the 58 medically treated patients who presented with cholesterol emboli was significantly reduced $(\mathrm{p}=0.028)$. Stroke was the commonest cause of death and was significantly more frequent than in the general population $(\mathrm{p}<0.001)$; there was also an increased total incidence of cerebrovascular disease (fatal and non-fatal) compared with the Oxfordshire Stroke Project $(p<0.001)$. The mortality from ischaemic heart disease was not significantly increased.

We report a series of 85 patients with retinal emboli, 69 of whom had cholesterol emboli (70 fundi), 15 calcific emboli and one platelet-fibrin embolus. The natural history of medically treated patients with cholesterol emboli is compared both with an age and sex matched population and with patients with amaurosis fugax but no visible retinal emboli.

Emboli in retinal arteries may occur in the absence of any visual symptoms. Sometimes they may be seen during or after an attack of temporary visual loss; at other times they are observed in patients with established uniocular field defects. Emboli may be composed of fibrin-platelet aggregates, cholesterol fragments, particles of calcified cardiac valve ${ }^{1}$ or other less common material such as mixed or infected thrombus, neoplasm, fat, air or foreign material. Amaurosis fugax is most commonly ascribed to retinal embolism although other causes may also be important. $^{23}$

There are a few descriptions of the passage of white emboli through the retinal circulation during attacks of transient visual loss. ${ }^{45}$ Fibrin-platelet emboli of this type usually arise from mural thrombus in the internal carotid artery formed on the surface of an atheromatous plaque or ulcer. The duration of attacks is usually short and corresponds to the passage of an embolus through the retinal circulation; these emboli are rarely observed.

Witmer and Schmid ${ }^{6}$ reported cholesterol crystals in retinal arterioles but Hollenhorst ${ }^{7}$ first recognised and stressed the significance of these shiny yellow

Address for reprint requests: Dr R W Ross Russell, Department of Neurology, St Thomas' Hospital, London SE1 7EH, UK.

Received 24 October 1986 and in revised form 31 December 1986. Accepted 5 January 1987 plaques in retinal arterioles of patients with atherosclerotic carotid disease, who may suffer transient visual loss. Cholesterol emboli lodge at points of branching of retinal arterioles or at the lamina cribrosa. Over days or weeks they fragment and disappear or are dispersed into the peripheral retina. They may be seen on routine ophthalmoscopy after an episode of transient visual loss and fluorescein angiography shows that the emboli are no longer obstructing blood flow through the vessel; the reason for this lies in the flat shape of the cholesterol crystal which tends to impact with its long axis in the direction of flow. On other occasions cholesterol emboli may cause permanent visual loss or create a localised giant cell foreign body reaction in the wall of the artery.

Calcific emboli are derived from degenerate cardiac valves; they usually result in permanent visual loss of fibre bundle type. Such an embolism is white, nonrefractile and usually single; it tends to persist indefinitely in the retinal circulation and rarely causes recurrent attacks.

\section{Patients and methods}

The 85 patients had been seen at St Thomas' Hospital Medical Eye Unit between 1973 and 1984. Clinical details were obtained from case notes; these included presenting symptoms and signs, the presence of hypertension (diastolic blood pressure equal to or greater than $110 \mathrm{~mm} \mathrm{Hg}$ or on treatment), ischaemic heart disease (angina or previous myocardial infarction), intermittent claudication, diabetes mel- 
litus, previous transient ischaemic attack, amaurosis fugax or stroke, and smoking habits. In the examination note was taken of the position and type of retinal embolus. the visual acuity and field loss, the presence of carotid bruits and abnormalities in the cardiovascular system. Amaurosis fugax was defined as partial or complete uniocular visual loss of sudden onset lasting less than one hour and stroke as an episode of focal neurological deficit of sudden onset lasting more than 24 hours. The results of special investigations including echocardiography and angiography were noted.

All except two of the surviving patients were traced by contacting the patients themselves or the General Practitioner by letter and telephone. If the patient had deceased, a copy of the death certificate was obtained from the Office of Population, Censuses and Surveys. The information sought from the patient and General Practitioner included the occurrence of any further amaurosis fugax, transient ischaemic attacks, stroke, vascular or hypertensive disease, further systemic disease and medication.

Survival curves were used to assess whether patients suffering visual loss due to retinal emboli had a different mortality rate from that of the normal population of similar age and sex. Assuming that the national death rate applied, we determined the expected number of deaths from the 1979 mortality figures for England and Wales as published by the Office of Population, Censuses and Surveys. ${ }^{8}$ For fatal ischaemic heart disease ICD codes $410-414$ and for fatal cerebrovascular disease ICD codes $430-438$ were used. The observed and expected number of deaths over the 6 years was compared using Poisson distribution probabilities. The incidence of stroke was compared with yearly age and sex specific incidence rates for the first stroke, observed by the Oxfordshire Community Stroke Project. ${ }^{9}$

\section{Results}

Eighty-five patients (61 male, 24 female) with retinal emboli, who presented with monocular visual loss, were identified from hospital records. In 17 patients the visual loss was transient (less than 4 hours) whilst in the remaining 68 patients the visual loss was permanent. The distribution according to age and sex is shown in table 1. The average duration of follow up until December 1985 or death was 4.5 years (range 12 months to 12 years): 11 patients were followed up for one year, 47 for one to five years, 18 for six to nine years and seven for over 10 years; two patients were lost to follow up.

\section{Table I Age at presentation}

\begin{tabular}{lccc}
\hline Age (rears) & Male & Female & Total \\
\hline $35-44$ & 2 & 0 & 2 \\
$45-54$ & 10 & 3 & 13 \\
$55-64$ & 22 & 11 & 33 \\
$65-74$ & 25 & 9 & 34 \\
$75-84$ & 2 & 1 & 3 \\
Range 41-84 years, mean 63.0 years. & & \\
\hline
\end{tabular}

Cholesterol emboli

Cholesterol emboli were observed in 69 patients (52 male, 17 female). Eleven of these patients subsequently underwent carotid endarterectomy. All the remaining 58 patients had received medical advice such as stopping smoking and losing weight, some had taken anti-hypertensive medication, aspirin and/or dipyridamol. Risk factors when first seen are shown in table 2.

Unilateral carotid bruits were present in 18 patients and bilateral in a further six. Carotid angiography, performed in 48 patients, showed carotid disease in 39 (including all the surgical group). This consisted of stenosis of the internal carotid artery in 15 patients, irregularity in 14, occlusion in seven, aneurysm of the internal carotid artery in one and irregularity of the siphon in two patients. The echocardiogram was abnormal in 15 of 35 patients. Hypertensive changes were seen in seven patients, aortic valve abnormalities in four and mitral valve abnormalities in four.

The emboli were single in 55 fundi and multiple in 15 (one patient had emboli in both fundi). The distribution of the cholesterol emboli is summarised in table 3. Forty-seven of the 91 cholesterol emboli were noted in the temporal field or on the disc. The visual acuity had deteriorated to $6 / 18$ or worse in 24 of the eyes in which cholesterol emboli were observed. The pattern of field loss is summarised in table 4.

Carotid endarterectomy was performed on 11 patients. In three cases the endarterectomy was performed on the side opposite the retinal emboli as this contralateral stenosis was considered to be critical or

Table 2 Risk factors

\begin{tabular}{lll}
\hline & $\begin{array}{l}\text { Cholesterol } \\
\text { emboli } \\
n=69\end{array}$ & $\begin{array}{l}\text { Calcific } \\
\text { emboli } \\
n=15\end{array}$ \\
\hline $\begin{array}{l}\text { Smoking (>20 cigarettes daily) } \\
\begin{array}{l}\text { Hypertension ( } \geqslant 110 \mathrm{~mm} \mathrm{Hg} \text { diastolic } \\
\text { or on treatment) }\end{array}\end{array}$ & 41 & 9 \\
$\begin{array}{l}\text { Ischaemic heart disease (angina or } \\
\text { previous myocardial infarction) }\end{array}$ & 25 & 8 \\
$\begin{array}{l}\text { Intermittent claudication } \\
\begin{array}{l}\text { Diabetes mellitus } \\
\text { Previous stroke }\end{array}\end{array}$ & 12 & 3 \\
$\begin{array}{l}\text { Previous amaurosis fugax or } \\
\text { transient ischaemic attack }\end{array}$ & 2 & 3 \\
\hline
\end{tabular}

Table 3 Distribution of emboli

\begin{tabular}{lcc}
\hline & Cholesterol & Calcific \\
\hline Inferior temporal & 34 & 7 \\
Superior temporal & 23 & 5 \\
Inferior nasal & 10 & 0 \\
Superior nasal & 8 & 0 \\
Central retinal artery & 14 & 3 \\
Cilioretinal artery & 2 & 0 \\
Total & 91 & 15 \\
\hline
\end{tabular}


Table 4 Visual loss

\begin{tabular}{lll}
\hline & $\begin{array}{l}\text { Cholesterol } \\
\text { emboli } \\
n=69\end{array}$ & $\begin{array}{l}\text { Calcific } \\
\text { emboli } \\
n=I 5\end{array}$ \\
\hline $\begin{array}{ll}\text { Diminished visual acuity } \\
\text { Permanent field loss: }\end{array}$ & 24 & 0 \\
None & 13 & 3 \\
Scotoma & 9 & 1 \\
Altitudinal & 21 & 10 \\
Arcuate & 22 & 1 \\
Constriction & 1 & 0 \\
Others & 1 & 0 \\
Unobtainable & 2 & 0 \\
\hline
\end{tabular}

because the internal carotid artery on the side of the emboli was occluded.

\section{Calcific emboli}

Calcific emboli were observed in 15 patients (seven male, eight female). Two of these patients subsequently underwent carotid endarterectomy. Risk factors at presentation are summarised in table 2 .

Clinical examination and echocardiography demonstrated a cardiac abnormality in 11 patients. These consisted of mitral valve disease in four (including two patients with mitral valve prolapse), aortic valve abnormalities in two patients, mixed valve disease in two and hypokinetic ventricular wall in three. The emboli were single in each fundus and the distribution

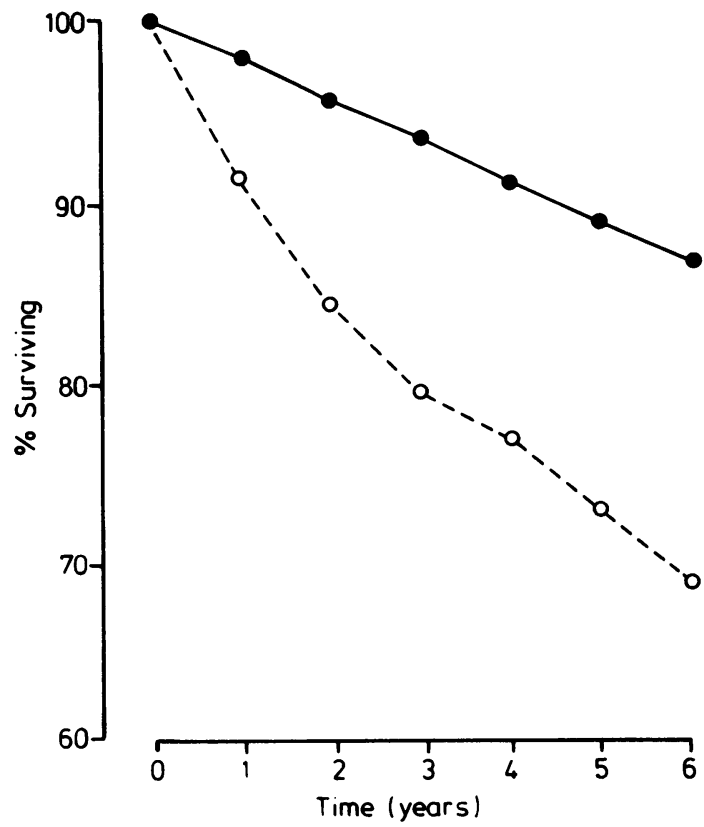

Fig 1 Survival curve for males and females combined after presentation with visual loss due to cholesterol emboli, compared with the expected survival for the equivalent age and sex in England and Wales, 1979. is summarised in table 3. Field loss was noted in 12 patients (table 4).

\section{Fibrin-platelet embolus}

A fibrin-platelet embolus was noted in one patient. In this patient a carotid bruit was audible and carotid angiography revealed a stenosis of the internal carotid artery. There was no permanent visual loss. This patient underwent carotid endarterectomy.

\section{MORTALITY}

Cholesterol emboli (non-surgical group)

Sixteen $(27.6 \%)$ of the group have died, the commonest cause of death was cerebrovascular disease (nine patients), the other causes were myocardial infarction (three patients), pulmonary disease (three patients), and ruptured aortic aneurysm (one patient). At 6 years of follow up, in the non-surgical group, the estimated mortality rate for the observed population was $31.4 \%$ compared with an expected mortality for a matched population of $13.5 \%(p=0.028)$ (fig 1$)$. The observed mortality after six years in males was $38.4 \%$ compared to an expected rate of $18.4 \%$ and in females $12.5 \%$ compared with an expected rate of $14.5 \%$. The mortality from fatal stroke after 6 years in the observed group was $21.9 \%$ compared to an expected mortality of $1.8 \%$ (fig 2 ). This is a significant difference in mortality from fatal stroke $(p<0.001)$. The incidence of cerebrovascular accident (fatal and non-fatal) in the observed population was $24.9 \%$ after 6 years, compared to an expected incidence (Oxfordshire Community Stroke Project) for first

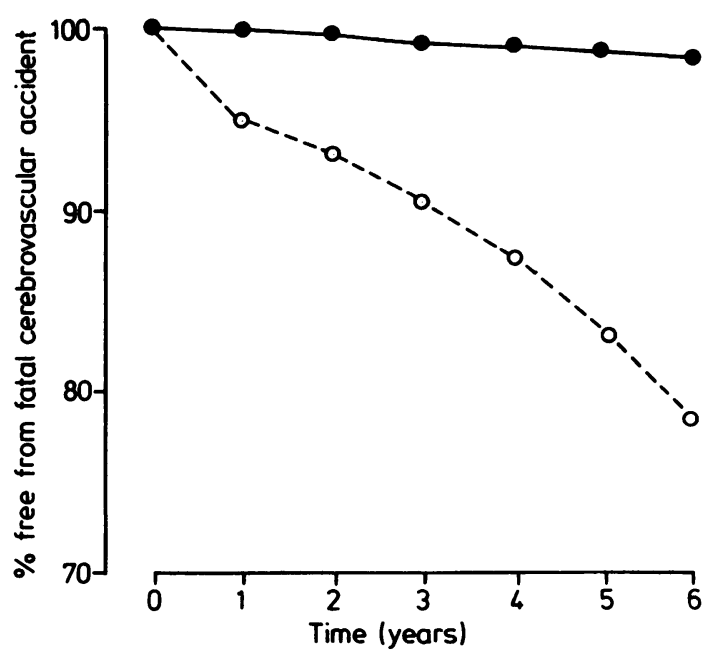

Fig 2 Survival free from fatal stroke for males and females combined after presentation with visual loss due to cholesterol emboli, compared with the expected survival for the equivalent age and sex in England and Wales, 1979. 


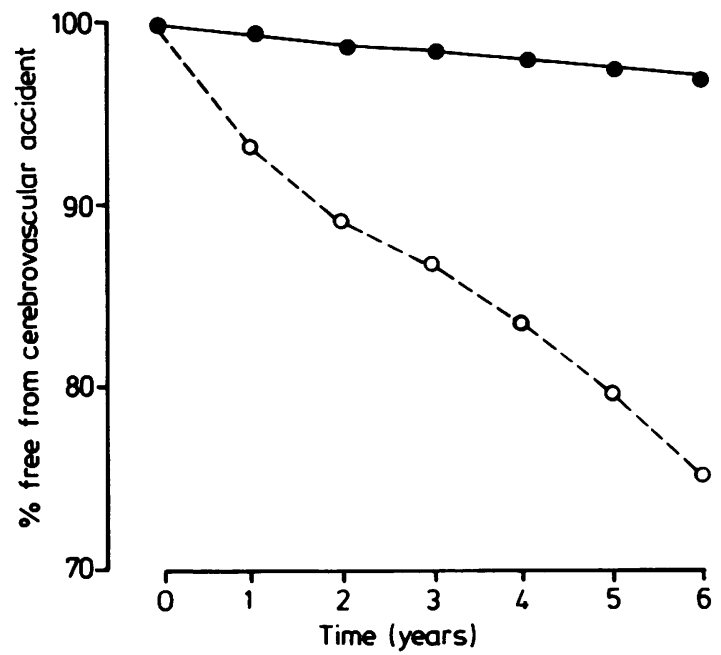

Fig 3 Survival free from stroke (fatal and non-fatal) for males and females combined after presentation with visual loss due to cholesterol emboli, compared with the expected stroke rate for the equivalent age and sex in Oxfordshire, I981-83.

stroke of $3.7 \%$ (fig 3 ). This difference is significant $(\mathrm{p}<0.001)$. Death from myocardial infarction (three out of 58 patients) was not significantly different from that expected in an age and sex matched group.

Other causes of morbidity during the follow up period in the non-surgical group included continued amaurosis fugax (five patients), further transient ischaemic attacks (two patients), both amaurosis fugax and transient ischaemic attacks (three patients) and further myocardial infarction (two patients).

\section{Cholesterol emboli (surgical group)}

Of the 11 patients with cholesterol emboli who underwent carotid endarterectomy, two patients have died, one due to myocardial infarction and one due to a mesenteric embolus. One patient has continued to suffer amaurosis fugax.

\section{Calcific emboli}

Four of the patients with calcific emboli have subsequently died, two from myocardial infarction and two from carcinomatosis. One patient has suffered a subsequent stroke and three have continued to suffer transient visual loss. The two patients who underwent carotid endarterectomy remained well.

\section{Fibrin-platelet embolus}

The patient with a fibrin-platelet embolus underwent carotid endarterectomy but subsequently suffered a myocardial infarction.

\section{Discussion}

Since visible cholesterol plaques do not arise de novo in retinal arteries, the finding of cholesterol emboli indicates an ulcerated, atheromatous plaque acting as an embolic source. ${ }^{10}$ In the present series of 69 patients with visible cholesterol emboli, $42(60.9 \%)$ showed either clinical or angiographic evidence of a carotid lesion. The source of the emboli in the remaining $27(39 \cdot 1 \%)$ patients is uncertain. Although emboli may arise from atheroma in the ascending aorta, a more likely source in the 12 hypertensive patients is the ophthalmic artery or central retinal artery. ${ }^{11}$

The present series of patients with retinal emboli is slightly older than a recent series of patients who suffered amaurosis fugax. ${ }^{12}$ This may be explained by the absence of patients who suffer "benign amaurosis fugax" which occurs in young patients and appears to be unrelated to atherosclerosis.

The incidence of death over the 6 years following the observation of a cholesterol embolus was $2 \cdot 3$ times the expected incidence in an age and sex matched population $(p=0.028)$. This is greater than the excess mortality found in patients with amaurosis fugax. ${ }^{12}$ At 6 years the incidence of fatal stroke was 12 times greater than expected $(p<0.001)$ and the total incidence of stroke was nine times greater than the expected incidence for first stroke quoted by the Oxfordshire Community Stroke Project ${ }^{9}(p<0.001)$. There were 10 strokes during the first 6 years of follow up, that is an average stroke rate of $2.9 \%$ per annum. This is a much greater increase in stroke incidence than was observed in patients with amaurosis fugax ${ }^{12}$ although the incidence of fatal cardiac events was not significantly increased.

Pfaffenbach and Hollenhorst ${ }^{13}$ published a follow up study of 208 previously reported patients ${ }^{14}$ with embolic cholesterol crystals in the ocular fundus; $12.0 \%$ of these patients presented with visual symptoms, $29.3 \%$ with stroke and $36.5 \%$ with other manifestations of generalised atherosclerotic vascular disease. After 7 years $112(53.8 \%)$ of the patients had died and by the end of follow up (up to 15 years) 135 $(64.9 \%)$ had died. Eighty-one (38.9\%) of the patients had died due to atherosclerotic cardiac disease while only $14(6.7 \%)$ suffered strokes. The explanation for the difference between this series and the present study may lie in the pattern of presentation. In the series of Pfaffenbach and Hollenhorst only a small proportion of patients had symptoms related to the retinal embolus whilst all the patients in the present study had presented because of ocular symptoms. The prevalence of coexisting atherosclerotic vascular disease and other risk factors were also greater in the series of Pfaffenbacher and Hollenhorst.

Savino, Glaser and Cassady ${ }^{15}$ reported a series of 
86 patients who presented with branch or central retinal artery occlusion or in whom symptomless retinal emboli were observed. Unspecified retinal emboli were visible in $\mathbf{4 9}$ fundi. The authors noted a highly significant decrease in survival amongst the embolic group when compared to an age and sex matched population and to the non-embolic group of patients. Although cardiovascular disease was the most frequent cause of death, there was a significant four to five fold increase in stroke mortality. The finding of an increased mortality and stroke incidence amongst patients with retinal emboli is comparable to the present series.

The amount of visual loss due to retinal emboli is unpredictable, ${ }^{16}$ cholesterol emboli may be an incidental finding in symptomless patients, others may have transient visual loss and some have permanent visual loss of a type suggesting occlusion of a branch or central retinal artery. In the present series of 68 patients with permanent field defects, there was a poor correlation between the position of the emboli and the field loss. This is because such emboli may not cause a complete obstruction and frequently break up and are distributed to the peripheral vessels, whilst if there is permanent visual loss the emboli impact at vessel bifurcations.

A cardiac source for calcific emboli was demonstrated in 11 of the 15 patients and in two patients there was evidence of coexistent carotid artery disease. Three patients suffered recurrent visual symptoms and one suffered a further stroke but there were no deaths from cerebrovascular disease. Two patients died from cardiovascular disease and the continued morbidity in this group supports the suggestion that these patients should be referred for cardiac evaluation since the occurrence of embolism may be an early sign that the diseased valve is breaking up and surgical replacement may be indicated. ${ }^{17}$

The mortality rate following visual loss caused by cholesterol retinal emboli, is higher than that observed following amaurosis fugax. ${ }^{111819}$ The explanation lies, not only in the older age group of patients, but also because such emboli provide evidence of extensive and ulcerating atheroma.

In the present series the increased death rate observed in patients with cholesterol retinal emboli was mainly due to an increased incidence of fatal stroke. This suggests that the presence of cholesterol emboli within the retinal circulation usually signifies carotid atheroma and is an important predictor of subsequent cerebrovascular disease. How much of this is caused by accumulation of cholesterol emboli derived from the carotid artery in the cerebral arteries and how much by local atheromatous disease in smaller vessels is as yet undetermined, but the relative volume of cerebral and retinal circulation suggest that for every embolus seen in the retina many times that number must have been carried to the brain. Foci of cerebral infarction in border zone territories have been found in such patients and the surface pial arteries may be occluded by successive accretion of cholesterol emboli. ${ }^{20}$

If it were possible to identify the source of embolism to a localised accessible region of the internal carotid artery there would be good theoretical grounds for endarterectomy irrespective of whether or not the lesion was "haemodynamically significant". Such a policy has been advocated ${ }^{21}$ although never subjected to a controlled trial.

The appearances of the carotid artery on angiography may be deceptive and give a very inexact indication of the presence of thrombus or ulceration, ${ }^{22}$ and recent vascular surgical practice tends to favour endarterectomy for those lesions reducing the vascular lumen to $50 \%$ or less. These have been shown to be associated with high risk of cerebral ischaemic events. ${ }^{23}$

Although we did not include any patients in our study who did not have visual symptoms, there is no doubt from previous reports that cholesterol emboli are a frequent incidental finding in those with coronary or peripheral atherosclerosis. ${ }^{13}$ It remains to be seen if investigation and surgical treatment of the carotid tree should be extended to these patients.

We thank Richard Morris, Department of Community Medicine, for invaluable statistical advice and Miss V Spencer for typing the manuscript.

\section{References}

I Russell RWR. The source of retinal emboli. Lancet 1968;ii: 789-92.

2 Kendell RE, Marshall $\mathbf{J}$. Role of hypotension in the genesis of transient focal cerebral ischaemic attacks. Br Med J 1963;2: 344-8.

3 Cogan D. Blackouts not obviously due to carotid occlusion. Arch Ophthalmol 1961;66:180-7.

4 Fisher CM. Observations of the fundus oculi in transient monocular blindness. Neurology 1959;9:333:-47.

5 Russell RWR. Observations on the retinal blood vessels in monocular blindness. Lancet 1961;ii:1422-8.

6 Witmer R, Schmid A. Cholesterinkristall als retinaler arterieller embolus. Ophthalmologica (Basel) 1958;135:432-3.

7 Hollenhorst RW. Significance of bright plaques in the retinal arterioles. JAMA 1961;178:23-9.

8 Office of Population Censuses and Surveys. The Registrar General's decennial supplement for England and Wales. HMSO Series DH 1, 1979;8:6-27.

9 Oxfordshire Community Stroke Project. Incidence of stroke in Oxfordshire: first year's experience of a community stroke register. Br Med J 1983;287:713-6.

10 David NJ, Klintworth GK, Friedberg SJ, Dillon M. Fatal atheromatous cerebral embolism associated with bright plaques in the retinal arterióles. Report of a case. Neurology 1963;13:708-13.

11 Adams RD, Fisher CM. Pathology of cerebral arterial occlusion. 
In: Fields WS, ed. Pathogenesis and Treatment of Cerehrovascular Disease. Springfield, Illinois: Charles C Thomas, 1961.

12 Poole CJM, Russell RWR. Mortality and stroke after amaurosis fugax. J Neurol Neurosurg Psychiatry 1985;48:902-5.

13 Pfaffenbach DD. Hollenhorst RW. Morbidity and survivorship of patients with embolic cholesterol crystals in the ocular fundus. Am J Ophthalmol 1973;75:66-72.

14 Hollenhorst RW. Vascular status of patients who have cholesterol emboli in the retina. Am J Ophthalmol 1966;61:1159-65.

15 Savino PJ, Glaser JS, Cassady J. Retinal stroke. Is the patient at risk? Arch Ophthalmol 1977;95:1185-9.

16 Arruga J, Sanders MD. Ophthalmologic findings in 70 patients with evidence of retinal embolism. Ophthalmology 1982;89: 1336-47.

17 Russell RWR. Vascular Disease of the Central Nervous System.
Edinburgh: Churchill Livingstone. 2nd ed. 1983:218-9.

18 Marshall J, Meadows S. The natural history of amaurosis fugax. Brain 1968:91:419-34

19 Parkin PJ, Kendall BE, Marshall J, McDonald WI. Amaurosis fugax: some aspects of management. $J$ Neurol Neurosurg Psichictry 1982;45:1-6.

20 McDonald WI. Recurrent cholesterol embolism as a cause of fluctuating cerebral symptoms. J Neurol Neurosurg Psychiatry 1967:30:489-96.

21 Hooshmand H, Vines FS, Lee HM, Grindal A. Amaurosis fugax: diagnostic and therapeutic aspects. Stroke 1974;5:643-7.

22 Fisher CM, Ojemann RG. A clinicopathologic study of carotid endarterectomy plaques. Rev Neurol (Paris) 1986;142:573-89.

23 Harrison MJG, Marshall J. Prognostic significance of severity of carotid atheroma in early manifestations of cerebrovascular disease. Stroke 1982;13:567-9. 